\title{
LIFE EXTENSION TECHNIQUE FOR WELDED STRUCTURE USING HFMI/PIT: A REVIEW ON PAST AND CURRENT RESEARCHES WITH APPLICATIONS
}

\author{
Y. H. P. Manurung ${ }^{1}$, M. A. Mohamed ${ }^{1,2,3}$, D. Andud $d^{1,2,3}$

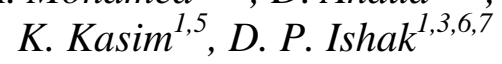 \\ ${ }^{1}$ Faculty of Mechanical Engineering, UiTM Shah Alam, MALAYSIA \\ ${ }^{2}$ University Kuala Lumpur Malaysia French Institute, Bangi, MALAYSIA \\ ${ }^{3}$ Technogerma Engineering \& Consulting, Shah Alam, MALAYSIA \\ ${ }^{4}$ Nusantara Technologies Sdn. Bhd., Shah Alam, MALAYSIA \\ ${ }^{5}$ Politeknik Sultan Salahuddin Abdul Aziz Shah, Shah Alam, MALAYSIA \\ ${ }^{6}$ University of Indonesia, Jakarta, INDONESIA \\ ${ }^{7}$ Bogor Safety Institute, Bogor, INDONESIA
}

A. Z. Abidin $^{1,3}$, S. Saidin ${ }^{1,4}$,

\begin{abstract}
In this paper, High Frequency Mechanical Impact (HFMI) using Pneumatic Impact Treatment (PIT) which can be applied for new or aging welded structure towards asset integrity will be discussed. The technology HFMI/PIT which falls under post weld treatment process is primarily aimed to enhance fatigue life and to strengthen welded joint. At first, the basic principle on fatigue of welded structure based on the IIW Recommendation will be briefly described. Further, various investigations conducted by prominent research universities or institutions and various industrial applications in European countries will be reviewed and discussed. Lastly, the current research on application of HFMI/PIT carried out under Advanced Manufacturing Technology Excellence Centre (AMTEx) at Faculty of Mechanical Engineering UiTM Shah Alam will be presented. As conclusion, it is stated that HFMI/PIT can be applied for extending the structural life and also for design optimization.
\end{abstract}

Keywords: HFMI, PIT, Weld Fatigue Integrity, IIW

*Corresponding author: Tel. +60-12-607 7056

E-mail: yupiter.manurung@gmail.com

\section{Introduction}

Failures due to fatigue in welded structures continues to be topic deserving wide focus due to its contributions to loss of life and substantial costs each year all over the world. Fatigue is still the principle cause for breakdown of welded structures in steel bridges, ship structures and offshore structures. Fluctuating loads during inservice conditions are constantly subjected to these types of structural details and components. The ever substantial improvement of the socio-economy has led to the need of structures with longer life cycles, better performance and lower weight. This will shore up extensive use of accurate and more efficient fatigue design methods and the design methods must be connected to quality requirements which can be understood and managed during production [1,2].

Fatigue cracks normally instigate and grow in the vicinity of welds when subjected to variable amplitude loading even if the dynamic stresses are reticent and well below the yield limit. It is common that the choice of material is very often optimized by choosing high strength material to allow for higher stresses and reduced dimension taking advantage of the yield criterion. However, the strength of the base material of the joining members is not the dominant factor for the fatigue strength of a welded joint. It is primarily governed by the local and global geometry of the joint. Hence, an increase in the yield stress may not improve the fatigue strength significantly. This makes the fatigue criterion a major issue. It is the fatigue strength that determines the final dimension of structural members such as stiffeners and the designated weld profile dimensions. The local weld geometry of the joint namely the weld profile dimension is highly dependent on the continuous development of welding techniques and production quality control. Welding without any improvement gives rise to local stress concentration, residual stresses and different types of defects, these features combined with high applied cyclic and complex service loading will give rise to failure due to fatigue [3]. 
A recent report under the Key Program 4 (KP4) "Ageing and Life Extension Program" written by the Health and Safety Executive (HSE) UK underlined that 'Ageing equipment is equipment for which there is evidence or likelihood of significant deterioration and damage taking place since new, or for which there is insufficient information and knowledge available to know the extent to which this possibility exists. The significance of deterioration and damage relates to the potential effect on the equipment's functionality, availability, reliability and safety. Just because an item of equipment is old does not necessarily mean that it is significantly deteriorating and damaged. All types of equipment can be susceptible to ageing mechanisms.' Inspections during this program also found not all structural analyses were up to date. Some fatigue and redundancy analyses were incomplete or missing and there was a need to clearly identify all the safety critical risks. Some installations designed to older rules had no fatigue assessments carried out. It is also stated in the report that analyses indicated ca $40 \%$ of the underwater jacket brace members had a reserve strength ratio less than 1.85 (reference ISO 19902), and ca $40 \%$ of the underwater brace members had welds with fatigue lives less than the operational life. While not a KP4 finding, the report stated that there have been recent reports of incidents of cracked teeth on jack-up mobile offshore drilling unit (MODU) legs [4].

Remedies to this situation include the introduction of various standards and fatigue design codes. The foundation of such codes rely, in some cases, on old concepts that do not easily translate to the output from modern computer programmed and are also limited to rather simplified structures. This instigated the International Institute of Welding (IIW) to develop the recommendations on fatigue of welded components and structures and on the effect of weld imperfections in respect to fatigue being first published in 1996 and updates finalized in 2006. This recommendation by the Commission XIII of IIW covers all current methods namely the nominal stress, structural stress, notch stress method as well as fracture mechanics assessment procedures. Fig. 1 shows the FAT value and stress cases.
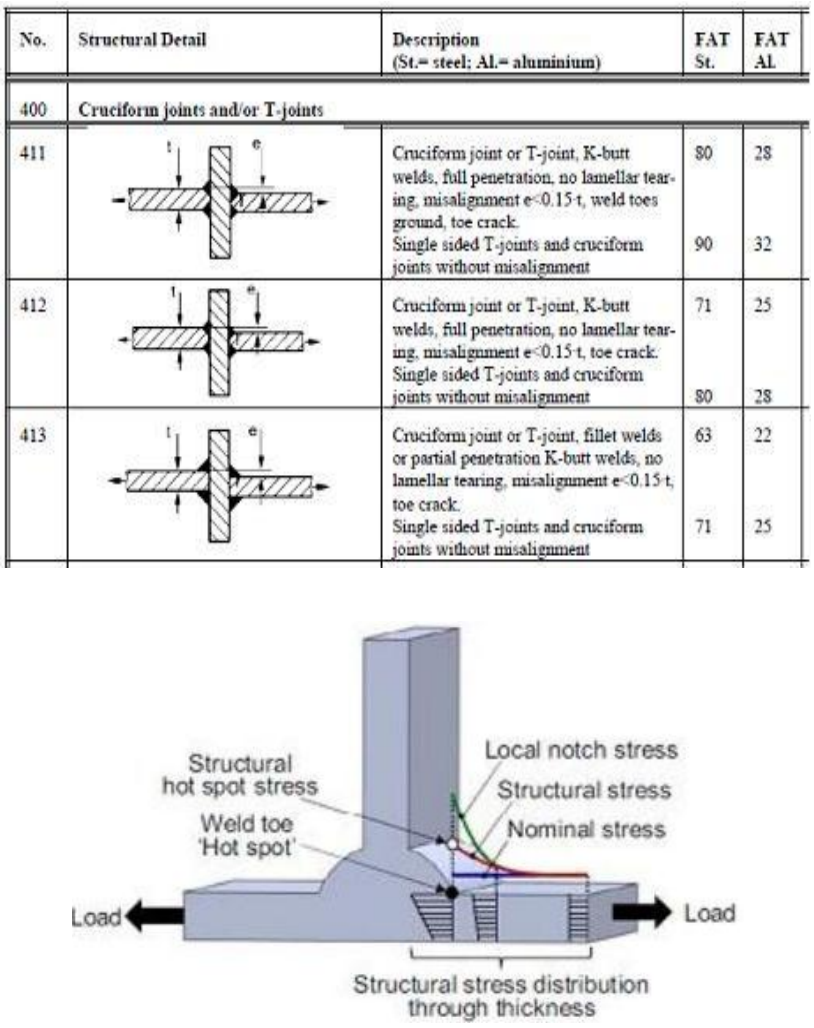

Fig. 1: Selection of FAT cases in the nominal stress assessment method (left) and Selection of stress cases definitions (right)

The determination of the fatigue life cycle of particular welded structures has led to the invention and development of various fatigue enhancement methods. The most notable methods are shot peening, burr grinding, ultrasonic impact technology (UIT), TIG dressing and Pneumatic impact treatment (PIT). However, the past decade has seen a remarkable development in the high frequency mechanical impact method (HFMI) as a reliable, effective and user-friendly method for post-weld fatigue enhancement technique for welded structures. Fatigue strength improvement factors in all of fatigue design methods for HFMI improved welds are defined as the characteristic fatigue strength at $\mathrm{N}=2 \times 10^{6}$ (FAT value) and on an assumed S-N slope of $m=5$. A comprehensive outline of most recently used method to fatigue assessment in the industry towards HFMI improved joints is presented in [6].

Many energy and process industry operating companies are experiencing the challenges of operating ageing assets, often beyond their design life. Hence life extensions have become a very important criterion of asset integrity. There is a need, often reinforced by regulation, to ensure safe, reliable and competitive operation today, but also into the future to the point where production ceases. 
Where ageing assets still have a considerable operating life remaining there are many benefits in determining a robust and dynamic life extension strategy. A good assets integrity plan will help deliver several things such as a safe and reliable operation into the future with regulations compliance in addition to appropriate maintenance and inspection actions. It will also have the advantages of having a strategic view of future investment needs and maintenance budgets with a clear clarity on the timing of major replacement and refurbishment needs. While the value of an asset integrity plan is clear, the most effective way of developing one is not. A good integrity plan must consider the assets themselves, the systems and organizations that support them and the competence of the people involved. The current and future projected condition, history, original design and future requirements must also be considered. Assessing every item of equipment, structure and pipe is neither practical nor necessary. Making the right judgments about the approach to developing an asset integrity plan and the level of detail to go into for each element are examples of the sort of critical decisions that must be made in building a successful plan in the most effective time and resource efficient manner.

\section{Results from Research University, Institution and Industrial Application using HFMI/PIT}

High Frequency Mechanical Impact (HFMI) using Pneumatic Impact Treatment (PIT) has emerged as a user-friendly, effective and reliable method for post-weld fatigue strength improvement technique on welded structures. During the past years, papers on HFMI/PIT technology for fatigue improvements had been presented within Commission XIII of the International Institute of Welding (IIW). Since 2008, various prominent research universities and institutions in European countries have been carrying out investigations on structural life and fatigue strength improvement using HFMI/PIT.

\subsection{Main Advantages of HFMI/PIT}

In many researches and applications, the selection of HFMI/PIT is mainly due to following advantages: (1) User-friendly, safe and low energy operation, (2) Fine adjustment by separate control of frequency and pressure, (3) Consistency during treatment process, (4) Impact intensity check prior to treatment process, (5) Clear treatment procedure for operator, (6) Outstanding quality result through inspection technique and (7) Capability for atmospheric and underwater treatment process.
Easy operation and low vibration are two important factors in selecting HFMI device. The operating gun of HFMI/PIT has merely weight of ca. $3 \mathrm{~kg}$ and vibration level of ca. $5 \mathrm{~m} / \mathrm{s}^{2}$. The outstanding hand arm vibration allows the maximum daily usage of this device up to 8 hours. In term of energy consumption, HFMI/PIT requires only $24 \mathrm{~V}$ and compressed air of 5 bar. Hence, the operation in confined space or on wet environment can be carried without worries of electrical danger.

Compared to other HFMI system, the newlydeveloped muscle system in HFMI/PIT allows fine pin movement which can be very precisely controlled with regard to kinematics, speed and force. It means that both frequency and force of impact can be controlled independently to each other which enable to vary the operating parameters for different materials. To keep the vibrations of HFMI/PIT as small as possible for the operator, an advanced spring system is developed to uncouple from impact force of this system. The spring system also ensures that the system's force of application is always constant, so that repeatability is maintained, even when the system is used by different operators. Fig. 2 shows the complete set of HFMI/PIT.
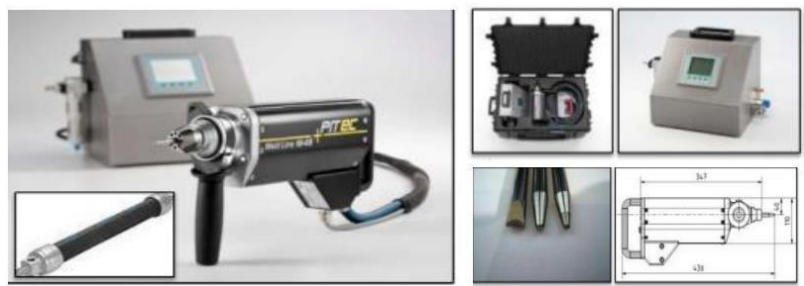

Fig. 2: Complete equipment set of HFMI/PIT

For ensuring the good quality resulted by treatment process, the intensity of device should be checked and measured regularly using specialdesigned intensity test prior to any application. A proposal for procedures and quality assurance for HFMI treated welded joints in steel was developed by PITEC GmbH to apply on steel structures with plate thicknesses ranging from 5 to $50 \mathrm{~mm}$ and for yield strengths from 235 to $960 \mathrm{MPa}$ by Marquis and Barsoum [6]. Fig. 3 shows the device for intensity test of device. 


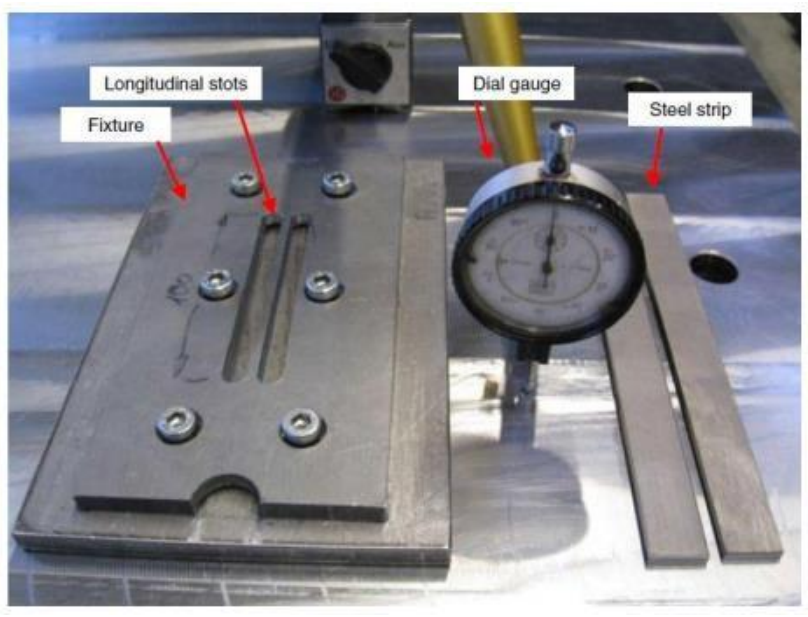

Fig. 3: Intensity test (Almen Test) developed by PITEC $\mathrm{GmbH}$

To achieve outstanding quality result, HFMI/PIT's quality monitoring guidelines with reference to the recent proposed procedures and quality assurance guidelines for HFMI-treated joints are established by Gerster et al. [7]. Fig. 4 exhibits the technique to assure the quality of HFMI/PITtreated surface.
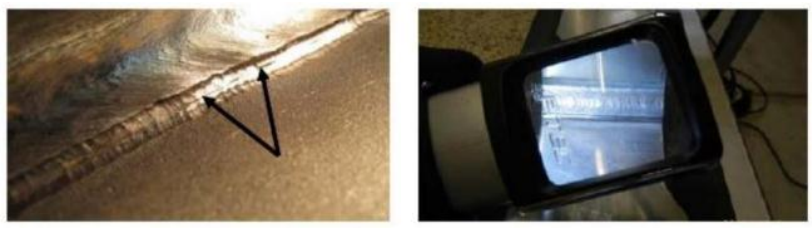

Fig. 4: Suitable quality assurance technique using digital/analog magnifier

Compared to conventional quality assurance method using depth gauge or caliper to measure the groove depth (normally max. $2 \mathrm{~mm}$ ), the quality monitoring technique for HFMI/PIT is carried out through visual inspection using digital or manual magnifier to ensure that no rest notch is available on treated surface. The decision on "no rest notch" surface inspection instead of just measurement of groove depth is due to following reasons: (i) no single groove dimension is optimal in all situations, (ii) material hardness at the weld toe may vary and hence treatment needs to be systematically adapted, (iii) deeper undercut is allowed based on quality standard (ex. ISO EN 5817, refer Table 1) and (iv) strong weld reinforcement possesses deep transition groove.

Table 1: Limits for imperfections for quality level

\begin{tabular}{|c|c|c|c|c|c|c|c|}
\hline No. & $\begin{array}{c}\text { ISO } \\
6520-1 \\
\text { reference }\end{array}$ & $\begin{array}{c}\text { Imperfection } \\
\text { designation }\end{array}$ & Remarks & \multicolumn{3}{|c|}{ Limits for imperfections for quality levels } \\
$\mathrm{mm}$ & \multicolumn{3}{|c|}{ D } & C \\
\hline
\end{tabular}

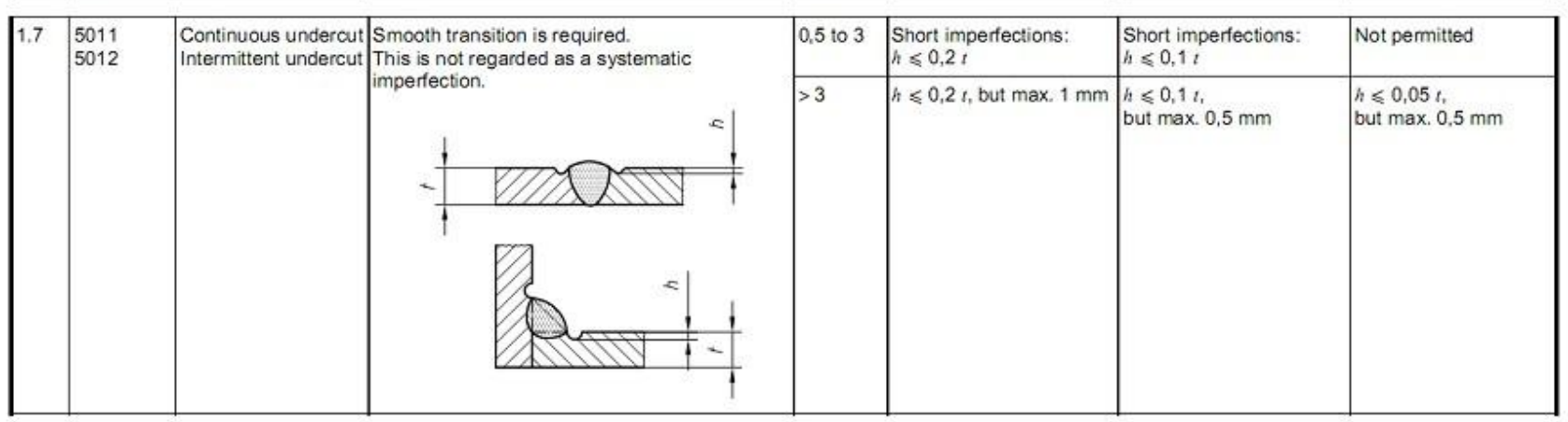

To ensure the good quality result, proper procedure for operator can be developed. This stepby-step operation procedure is named as HFMI/PIT
Treatment Procedure. Fig. 5 shows an example of treatment procedure. 

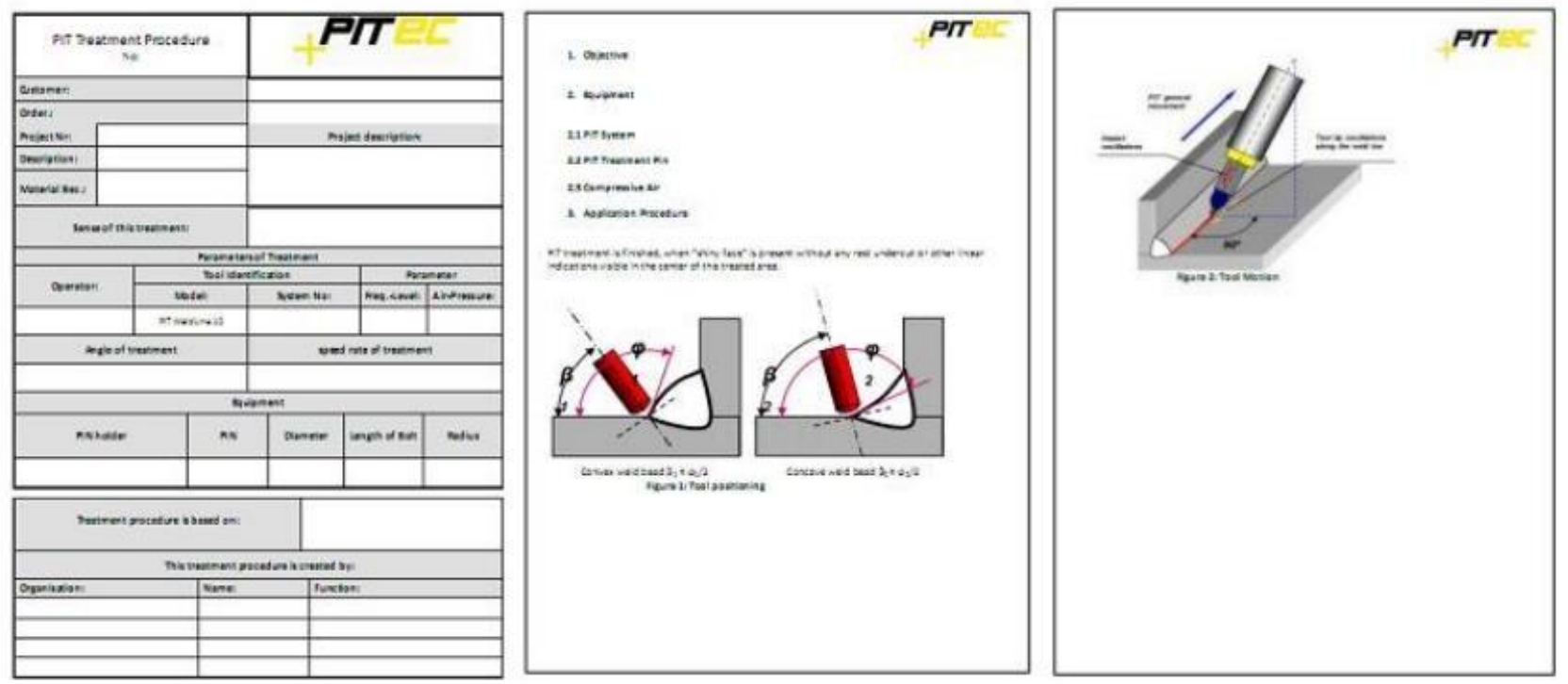

Fig. 5: HFMI/PIT treatment procedure

HFMI/PIT is capable to be applied at atmospheric and in underwater condition. For underwater treatment, the components are made of $\mathrm{CrNi}$-alloy against corrosion and the casing including holes and channel is manufactured by using rapid prototyping. A special seal is also designed against water entrance into the system. In order to avoid the blowing effect to the front side, a special designed component is developed which also ensures the pressure balance inside the portable gun system. Fig. 6 shows the underwater weld treatment.
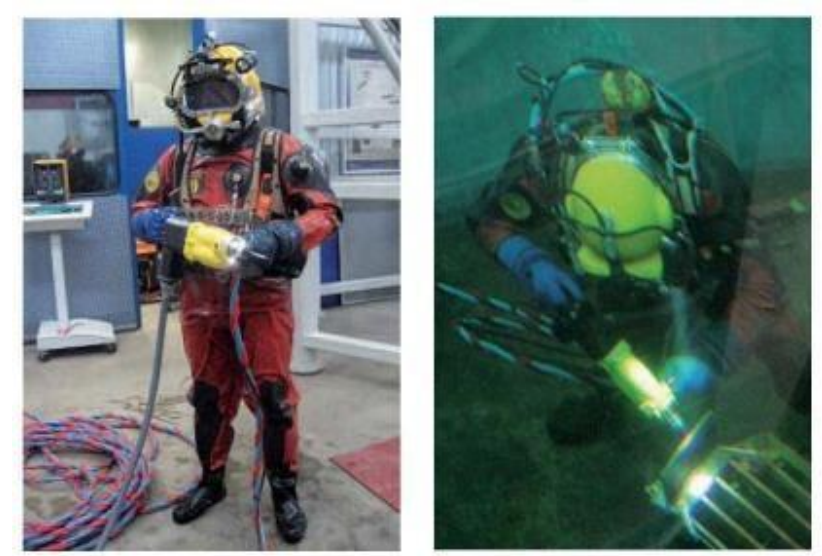

Fig. 6: Underwater treatment process using HFMI/PIT

\subsection{Research Results at Universities \& Research Institutions}

The past decade has seen several researches being conducted on the possible improvements of the fatigue life cycle using HFMI/PIT. Posttreatment techniques like the high frequency mechanical impact treatment (HFMI) exhibit a significant fatigue life enhancement of welded joints. In general this effectiveness is primary based on three effects, whereas the notch stress concentration at the weld toe is reduced, the local hardness increased and compressive residual stresses are induced.

At University Stuttgart in Germany, Kuhlmann [8] investigated experimentally the fatigue improvement peened by newly-developed HFMI/PIT. The investigation was carried out on material S355J2 and S690QL welded as butt and cruciform joint. It can be seen from the test report that the fatigue improvement factor (mean value) is 2.22 for 355 (cruciform joint), 1.82 for $\mathrm{S} 690$ (cruciform joint) and 1.38 for S355 (butt joint). Fig. 7 shows the $\mathrm{S} / \mathrm{N}$ curves as results of investigation. 

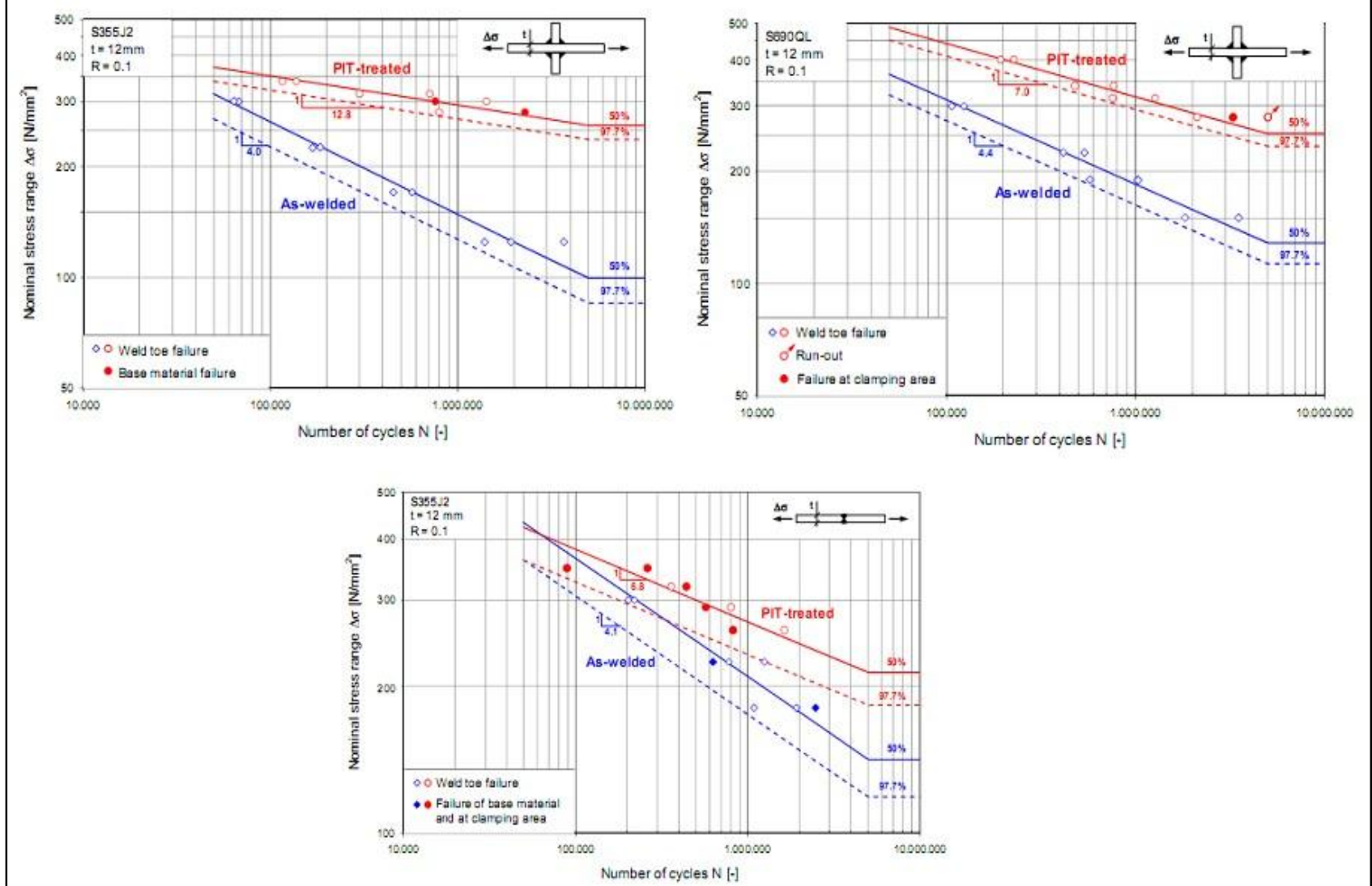

Fig. 7: Results of S/N curves for S355 (cruciform joint, left), S690 (cruciform joint, right) and S355 (butt joint, below)

For Bundesanstalt fuer Wasserbau or BAW (Federal Waterways Engineering and Research Institute) in Germany, a research [9] was conducted under collaboration between University of Stutgart and Karlsruhe Institute of Technology to investigate the effect of HFMI/PIT on fatigue strength improvement of mild steel (S235). Due to the lack of research on commonly used low carbon steel, this research was initiated and finalized in March 2013. In this investigation, there were four (4) trials which can be shown in the Table 2 .

Table 2: Results of research at BAW

\begin{tabular}{|c|l|l|}
\hline Trial & \multicolumn{1}{|c|}{ Treatment Process } & $\begin{array}{c}\text { Fatigue Strength } \\
\text { [in MPa] } \\
\text { at } \mathbf{N = 2 . 1 0 6} \text { cycle }\end{array}$ \\
\hline 1 & Welded - untreated & $81.4(\mathrm{~m}=3.0)$ \\
\hline 2 & Welded - treated & $182.3(\mathrm{~m}=11.8)$ \\
\hline 3 & $\begin{array}{l}\text { Welded - cyclic loaded - } \\
\text { treated }\end{array}$ & $105.9(\mathrm{~m}=4.72)$ \\
\hline 4 & $\begin{array}{l}\text { Welded - cyclic loaded till } \\
\text { crack - repair welding - } \\
\text { treated }\end{array}$ & $87.6(\mathrm{~m}=4.27)$ \\
\hline
\end{tabular}

At Belgian Welding Institute (BWI), an extensive investigation [10] was established in 2014. In this project, BWI investigated methods to improve the fatigue properties of welded joints in high strength steels (HSS) and this by different means. Two re-melting techniques (TIG- and Plasma dressing) and one mechanical technique HFMI/PIT were applied and compared. The general objective was to develop high performance welded joints in HSS in a thickness range of $5-10$ $\mathrm{mm}$ with improved fatigue properties. This investigation clearly shows the potential of the postweld treatment techniques. In Table 3, the increase in FAT class of dressed stiffeners and HFMI/PIT treated stiffeners compared to the current FAT class of 56 of Eurocode III $(\mathrm{m}=3)$ is listed.

Table 3: Results of research at BWI

\begin{tabular}{|c|c|c|c|}
\hline $\begin{array}{c}\text { Steel } \\
\text { Grade }\end{array}$ & $\begin{array}{c}\text { Thickness } \\
(\mathbf{m m})\end{array}$ & $\begin{array}{c}\text { Effect of } \\
\text { Dressing }\end{array}$ & $\begin{array}{c}\text { Effect of } \\
\text { HFMI/PIT }\end{array}$ \\
\hline S420MC & 5 & +29 & +93 \\
\hline S420MC & 10 & +46 & +86 \\
\hline S700MC & 5 & +61 & +109 \\
\hline S700MC & 10 & $+9^{*}$ & +170 \\
\hline
\end{tabular}

*Results are based on small quantity of specimens. 
At the University of Duisburg-Essen in Germany, Berg and Stranghoener [11] performed fatigue tests on four different welded details made of ultra-high strength steels S960, S1100 and S1300 to determine the influence of HFMI/PIT on the fatigue strength. The fatigue strength of HFMI/PIT treated

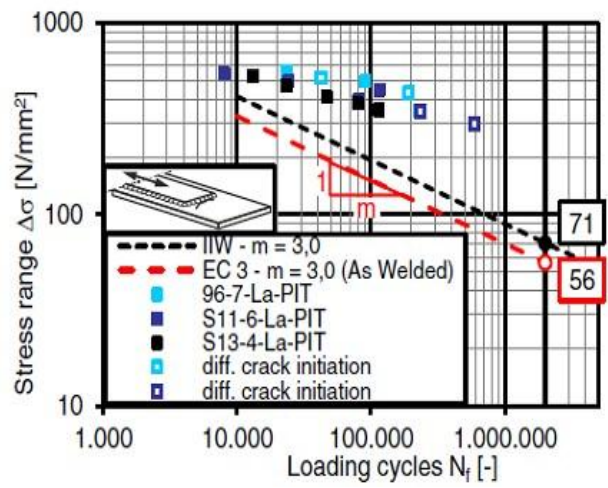

Fig. 8: Comparative test results of HFMI/PIT on weld toe

At University of Aalto in Finland, Yildirim and Marquis [12] perceived that the fatigue strength of improved welds increases with material yield strength. A design recommendation including one fatigue class increase in strength (about 12.5\%) for every $200 \mathrm{MPa}$ increase in static yield strength is proposed and are shown to be conservative with respect to all available data. Fig. 9 shows the increase of FAT value based on yield stresses.

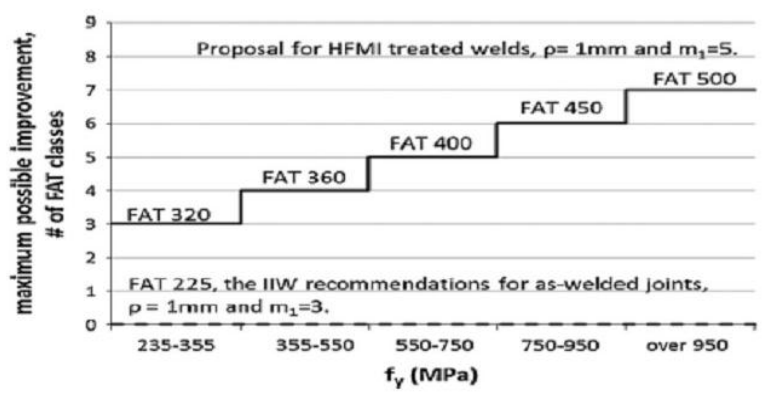

Fig. 9: FAT classes as a function of the fy

At Montan University in Austria, the effect of HFMI/PIT for mild structural steel (S355) up to ultra-high strength steel (S960) on fatigue was investigated by Leitner at al. [13] and it is concluded that the base material stress range can be reached for the high- strength steel joints with HFMI treatment while all fatigue test data points are above the IIWrecommendation, even if a bonus factor of 1.5 for HFMI treatment and a Benign Thinness bonus factor are considered. Fig. 10 shows the influence of HFMI/PIT and yield strength on fatigue cycle. specimens was at least twice the fatigue strength of the as welded toe condition. Fig. 8 shows the result for different joint types.
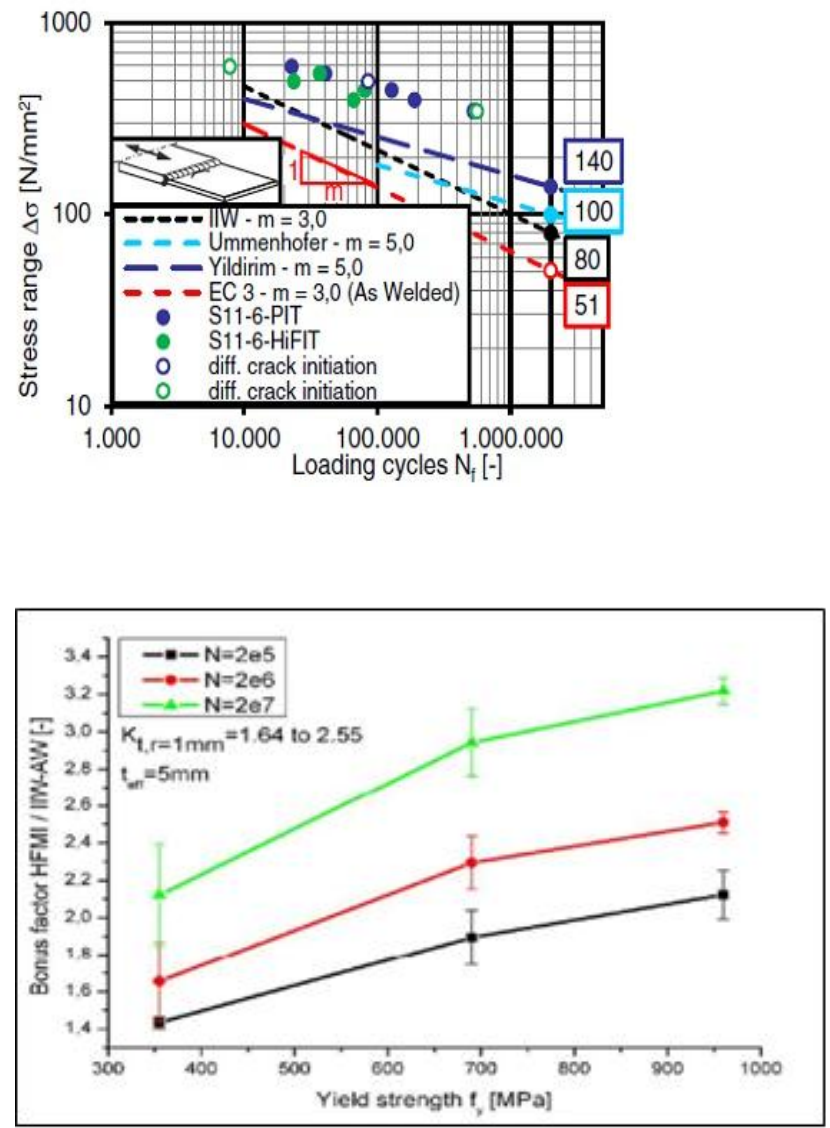

Fig. 10: Influence of base material yield strength on fatigue cycle

Still at Montan University, Simunek et al. [14] developed a simulation loop set-up including structural welding simulation, numerical computation of the HFMI/PIT-process, and finally, a numerical estimation of the local fatigue behaviour using FEM to compare the benefit of HFMI/PIT-treatment. As the simulation loop completed, they concluded that the amount of the tensile residual stresses reduced due to the induction of compressive residual stresses in the weld toe by the cyclic peening. Fig. 11 indicate the stress distribution and plastic deformation at the weld toe using the developed simulation loop. 


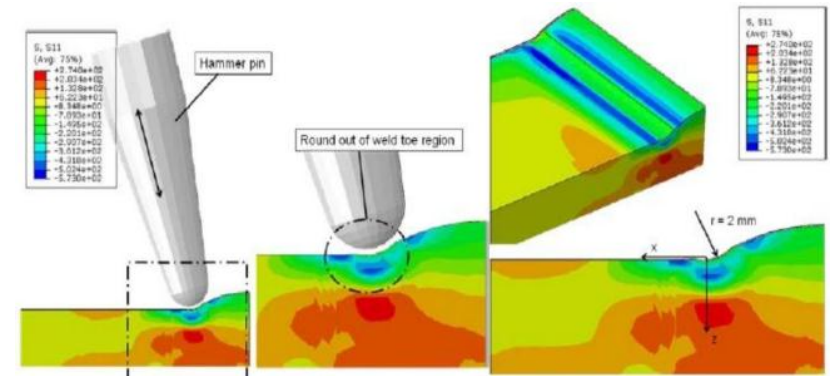

Fig. 11: Stress distribution and plastic deformation at the weld toe using the developed simulation loop

Leitner et al. [15] examined the effect of variable amplitude loading on the fatigue strength of HFMI/PIT-treated T-joints. Their primary aim was to assess the local fatigue strength of welded and HFMI post-treated high-strength steel joints of steels S690 and S960, and compared with common construction steel S355. They found that only a minor enhancement of the fatigue behaviour due to the HFMI-treatment compared to the as-welded condition is achieved for S355, while for S690 Tjoint specimen, the nominal $\mathrm{S} / \mathrm{N}$-curves depict a slight increase of about $25 \%$ in the fatigue strength due to the HFMI-treatment. However, for S960 T joint specimens show a fatigue resistance almost similar to that of the untreated base material in the low and even in the high-cycle fatigue regime. To sum up these experimental they concluded that HFMI/PIT post-treatment led to a significant fatigue enhancement, especially in the high-cycle fatigue region due to a shift of the transition knee point $\mathrm{Nk}$ to lower load-cycles as illustrated in Fig. 12.

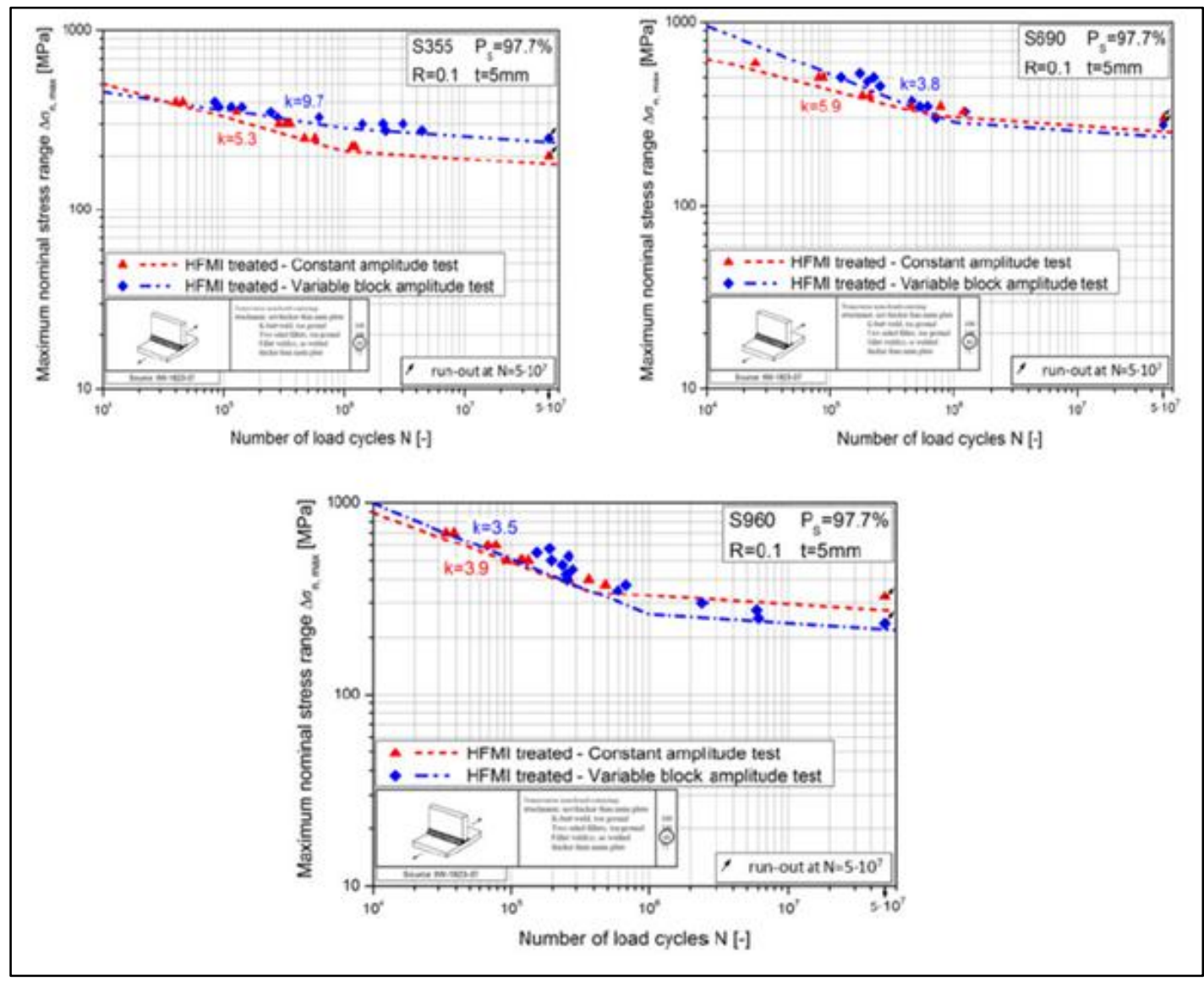

Fig. 12: Nominal S/N-curves for variable amplitude block loading - assessed with maximum (peak) nominal stress range

Martin Leitner et al [16] also investigated the influence of high frequency peening on fatigue life of high strength steels on three different weld seam geometries made of thin-walled high-strength steel, which are on butt joint, $\mathrm{T}$-joint and $\mathrm{T}$ joint with longitudinal attachment. They concluded that the butt joint treated with HFP achieved fatigue life almost similar to the fatigue strength of base metal, the T-joint Transition knee point Nk shifts to a lower number of load cycles implying a significant increase in endurable strength limit, while the longitudinal attachment HFP treated shows an increase of the slope $\mathrm{k}$ in the low-cycle fatigue regime. The data of these investigations are shown in Table 3, 4 and 5. 
Table 3 Fatigue test results for butt joint (nominal stress)

\begin{tabular}{|l|c|c|c|c|}
\hline & FAT [MPa] & $k[-]$ & $N_{\mathrm{k}}[-]$ & $1 / T_{\mathrm{S}}[-]$ \\
\hline As welded & 260 & 4.6 & $9-10^{5}$ & 1.11 \\
\hline HFP treated & 315 & 5.9 & $9-10^{5}$ & 1.09 \\
\hline
\end{tabular}

Table 4 Fatigue test results for T joint (nominal stress)

\begin{tabular}{|l|c|c|c|c|}
\hline & FAT [MPa] & $k[-]$ & $N_{\mathrm{k}}[-]$ & $1 / T_{\mathrm{S}}[-]$ \\
\hline As welded & 195 & 4.3 & $3 \cdot 10^{6}$ & 1.08 \\
\hline HFP treated & 315 & 3.9 & $4 \cdot 10^{5}$ & 1.12 \\
\hline
\end{tabular}

Table 5 Fatigue test results for longitudinal attachment (nominal stress)

\begin{tabular}{|l|c|c|c|c|}
\hline & FAT $[\mathrm{MPa}]$ & $k[-]$ & $N_{\mathrm{k}}[-]$ & $1 / T_{\mathrm{S}}[-]$ \\
\hline As welded & 120 & 3.2 & $3 \cdot 10^{6}$ & 1.04 \\
\hline HFP treated & 295 & 5.3 & $110^{6}$ & 1.09 \\
\hline
\end{tabular}

Martin Leitner et al [17] also investigated the crack propagation of the welded structure of the carbon steel S355 and rehabilitate its using post treatment HFMI. Around $1 \mathrm{~mm}$ pre-crack was occurred on the welded $\mathrm{T}$ joint of the carbon steel S355 before post treated with HFMI/PIT. After the fatigue test, they found the fatigue life of the specimen has a good agreement with the previous investigation as clarified in Fig. 13.
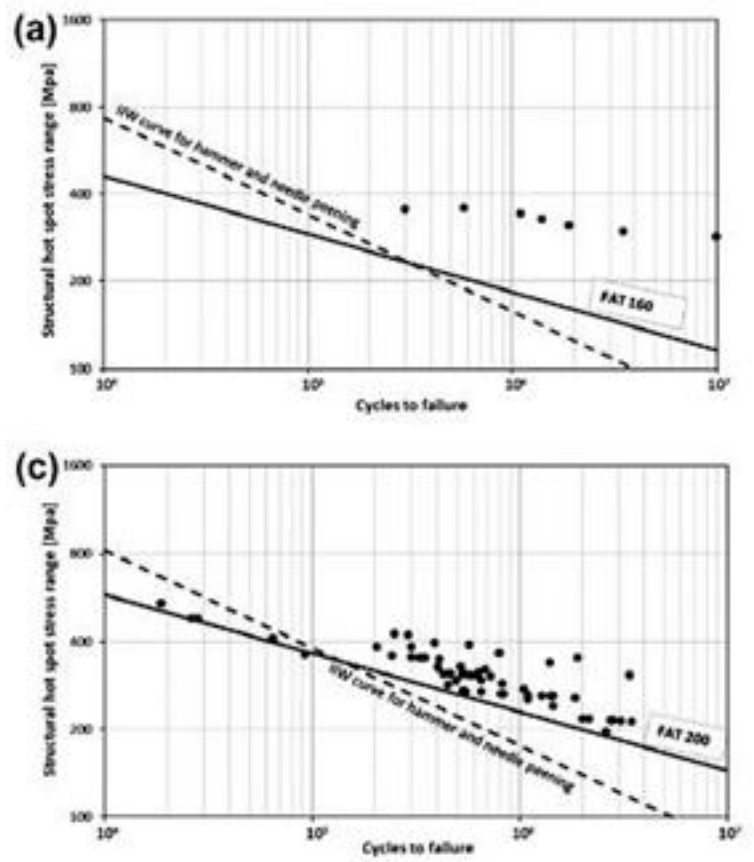

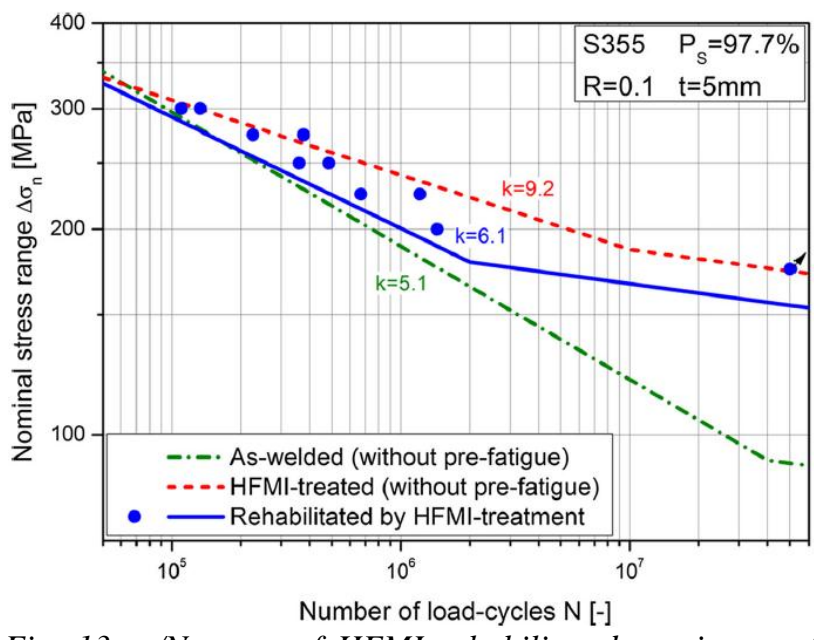

Fig. 13: a/N curve of HFMI rehabilitated specimens of welded carbon steel S355

At KTH - Royal Institute of Technology in Sweden, a comprehensive evaluation of published data for welded joints which had been improved using high frequency mechanical impact (HFMI) treatment was conducted in by Yildrim et al. [18] with proposed sets of characteristic fatigue strength curves as functions of yield strength. All of the design curves proposed are conservative with respect to available fatigue test data. Fig. 14 shows experimental data for non-load carrying HFMI-treated weld based on different yield strength.
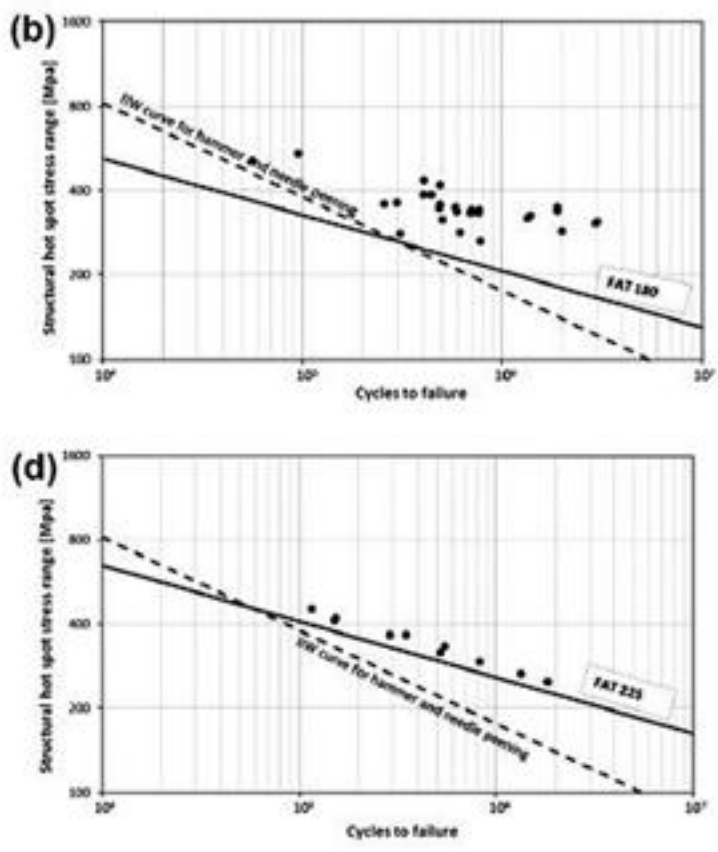

Fig. 14: Experimental data for non-load carrying HFMI-treated welds based on HSS. Proposed characteristic curves for: (a) $235<f y<355$, (b) $355<f y<550$, (c) $550<f y<750$ and (d) $750<f y<9$ 
At University of Braunschweig in Germany, Pagel et al. [19] investigated the influence of the high intensity on the fatigue strength of aluminum welds with HFMI/PIT and revealed that the fatigue strength of welded aluminium joints can be improved significantly with help of this method. Fig. 15 shows the comparative $\mathrm{S} / \mathrm{N}$ curves between experiment and EUROCODE 9.

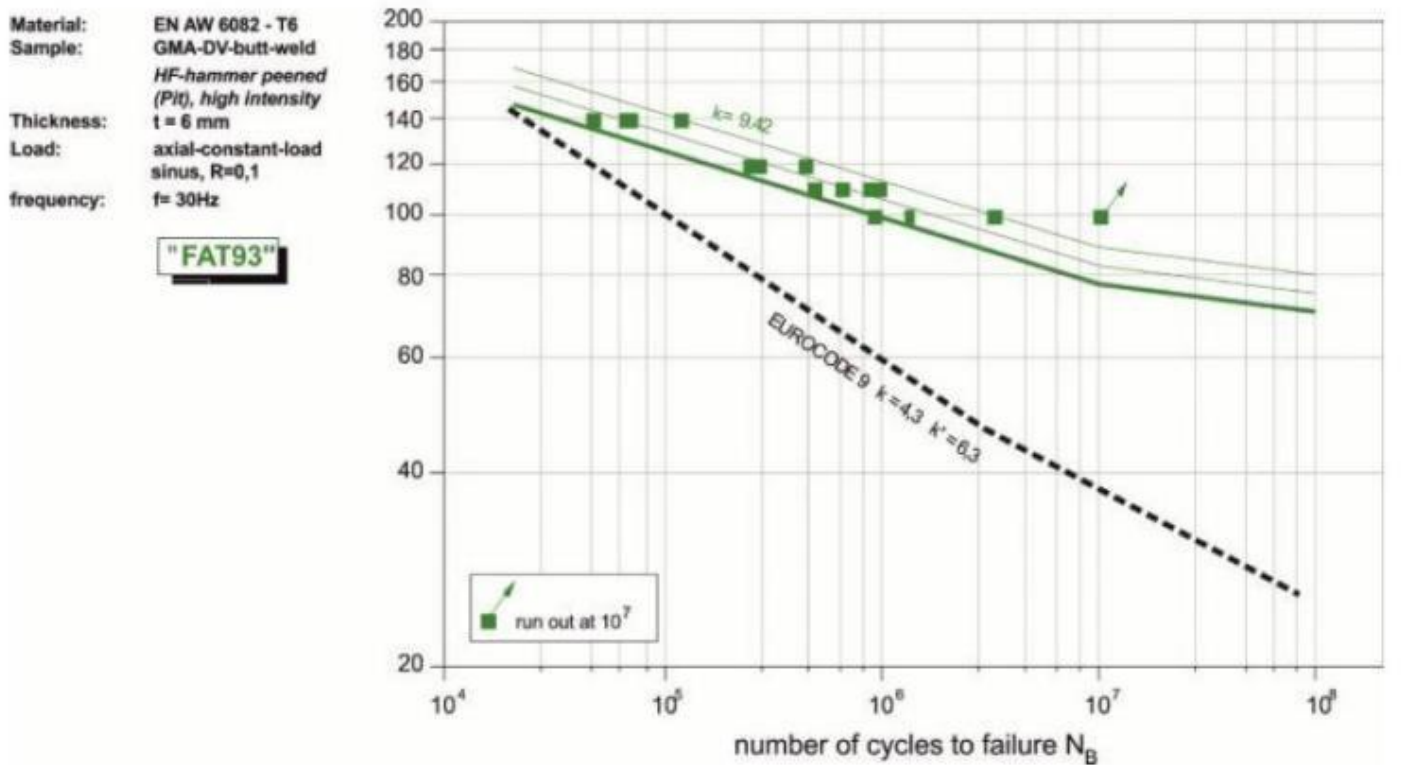

Fig. 15: SN-curves of DV-welds and calculated FAT-value using HFMI/PIT with high intensity

A comprehensive evaluation of published data is provided by Yildrim and Marquis [20] for welded joints improved by HFMI treatment to verify already-known fatigue classes for effective notch stress with the available axially-loaded fatigue data. The already-known fatigue classes are found to be conservative with respect to available fatigue test data.

These improvements are outlined in the IIW guideline for post-weld improvement [5] includes design resistance curves based on both the nominal stress assessment method and the structural hot spot stress method. Experimental data from recently published literature on enhancements of welded joints by HFMI peening found that an S-N slope of $m=5$ is suitable to be used for both the available HFMI treated fatigue data and the existing data for hammer peened welds. Fatigue strength improvement factors in all of fatigue design methods for HFMI improved welds are defined at $\mathrm{N}=2 \times 10^{6}$ and on an assumed S-N slope of $m=5$. Because the $\mathrm{S}-\mathrm{N}$ lines in the as-welded state follows a slope $m=3$ and, after HFMI treatment, the slope is changed to $m=5$, the computed improvement in fatigue strength changes as a function of $\mathrm{N}$. The FAT value after HFMI treatment for the cruciform joint shows an increment factor of 1.91 for a survival probability of $95 \%$ and an increment factor of 2.38 for a survival probability of 50\%. [21-24]. Haagensen [3], Yildirim and Marquis [25] and Maddox [26], had observed that the degree of improvement for HFMI treated and hammer peened welded components increases with material strength.

\subsection{HFMI/PIT-Applications at Various Industries}

Various industrial applications [7] have been conducted with the purpose of not only for fatigue strength improvement but also for mitigating the weld induced distortion. Linde Engineering in Schalchen, Germany [27] investigated the effect of HFMI/PIT on distortion of butt- welded plate with base material of P265GH. It was found out that the distortion can be reduced up to more than $30 \%$. Fig. 16 shows the effect of HFMI/PIT on weld distortion.
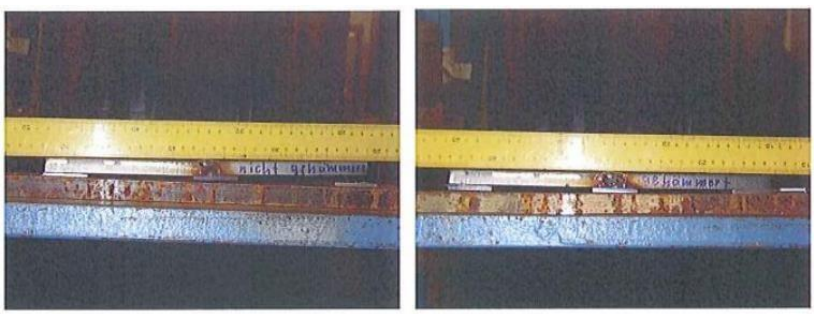

Fig. 16: Weld induced distortion without (left) and with (right) $\mathrm{HFMI} / \mathrm{PIT}$ 
TUV SUD Industry Service in Mannheim, Germany cooperated with technology developer for implementing HFMI/PIT within the scope of EUROCODE EN1993-1-9. It is concluded that the user or customer can benefit by using HFMI/PIT on fatigue life enhancement, simple maintenance concept, "slim" design and design optimization [28].

DCC Doppelmayr Cable Car GmbH applied HFMI/PIT to increase the life time of steel construction including tubular joints at the Oakland Airport in California. Due to the strict regulation for fatigue strength in USA, several fatigue tests were conducted prior to application under collaboration between University of Stuttgart in Germany and University of Seattle in USA. It is claimed by both universities that the lifetime is increased up to 4.5 times compared to as-welded condition. Fig. 17 exhibits the tubular joint construction treated by HFMI/PIT.

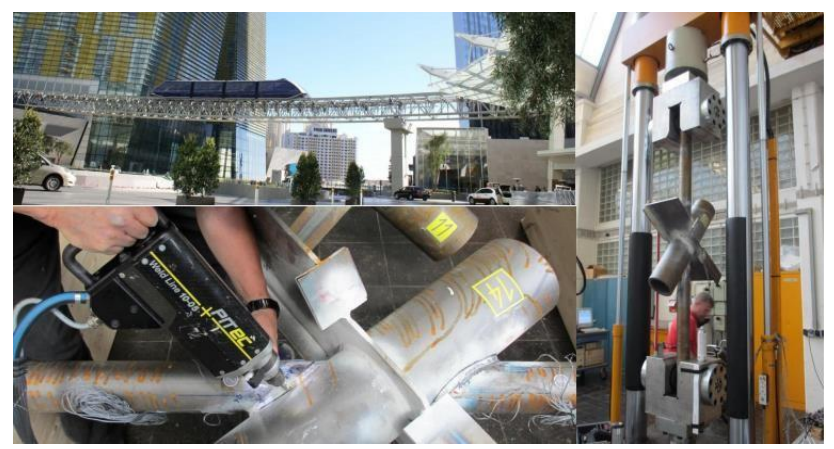

Fig. 17: Application of HFMI/PIT on tubular joint construction.

At Max Planck Institute for Plasma Physics in Germany, HFMI/PIT was used in the nuclear fusion reactor "Wendelstein 7-X" to reduce tensile residual stress on each weld. The base material was austenitic steel 1.4429 and filler metal material was 1.4455. The construction started in 2009 and was accomplished in 2014. The HFMI/PIT treatment is mainly used during the welding of many supports from the inner to the outer vessel wall. Fig. 18 shows the plasma vessel under construction and the HFMI/PIT treatment of each bead to keep the tensile stresses generated during welding to a minimum level.
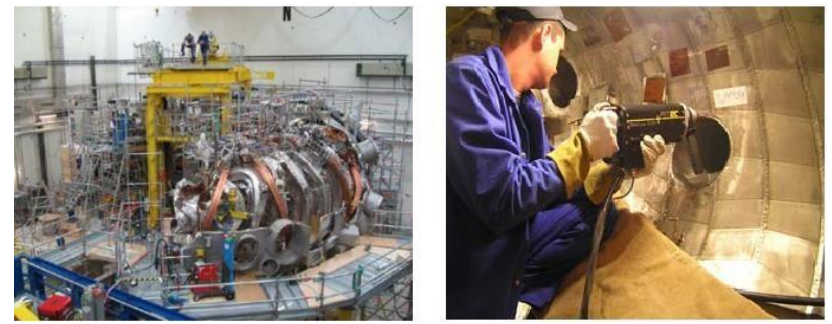

Fig. 18: Application of HFMI/PIT in the project "Wendelstein 7-X"

At SMS Siemag, HFMI/PIT was used to enhance the life time of ladle turret which is used for continuous casting. Based on the numerical calculations, the "hot spots" of the system were defined for the post-treatment. Fig. 19 shows an example of ladle turret with welded structure.

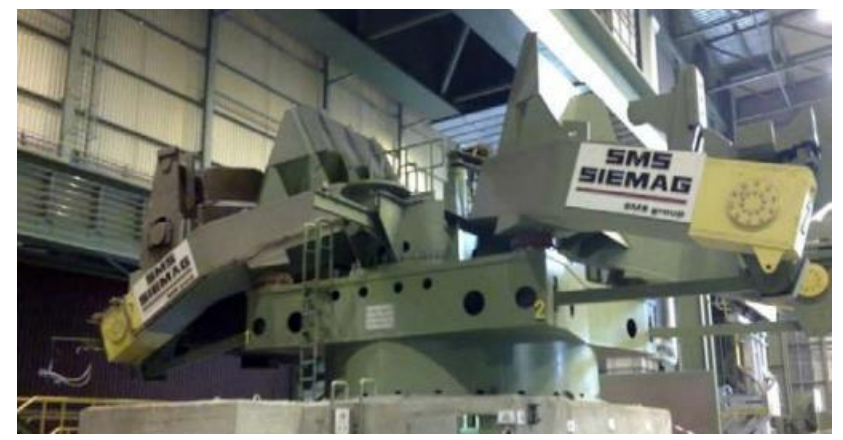

Fig. 19: Application of HFMI/PIT in Laddle Turret for continuous casting

At a train manufacturer in Austria, HFMI/PIT was used to enhance the fatigue life after repair welding for boogie section. It was recorded that at 3.2 million load-cycles cracks occurred which was repaired without HFMI/PIT-treatment. After 100,000 load-cycles, this section failed due to crack. Afterwards, each layer was repaired by using HFMI/PIT and no further crack was found. After 8.4 million load-cycles, a crack occurred on the opposite side at a stiffening rib. After 12 million load-cycles, the experiment was terminated. Fig. 20 shows the weld treatment using HFMI/PIT and test facility for analyzing fatigue of boogie.
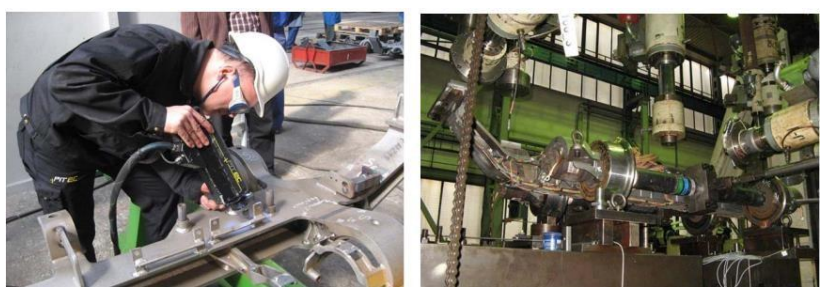

Fig. 20: Weld treatment using HFMI/PIT on train bogie and test facility 
Other industrial applications of HFMI/PIT include:

- Innovative maintenance in steel manufacturer

- Steel bridge

- Tower of wind energy plant

- Duplex mixer shaft

- Crane manufacturer

- Compressor damper

- Component of Press Machine

- Steam boiler

- Turbine housing

- Crane Structure

- Ship building

- Mass Rapid Transit (MRT)

- Roller shaft maintenance

- etc.

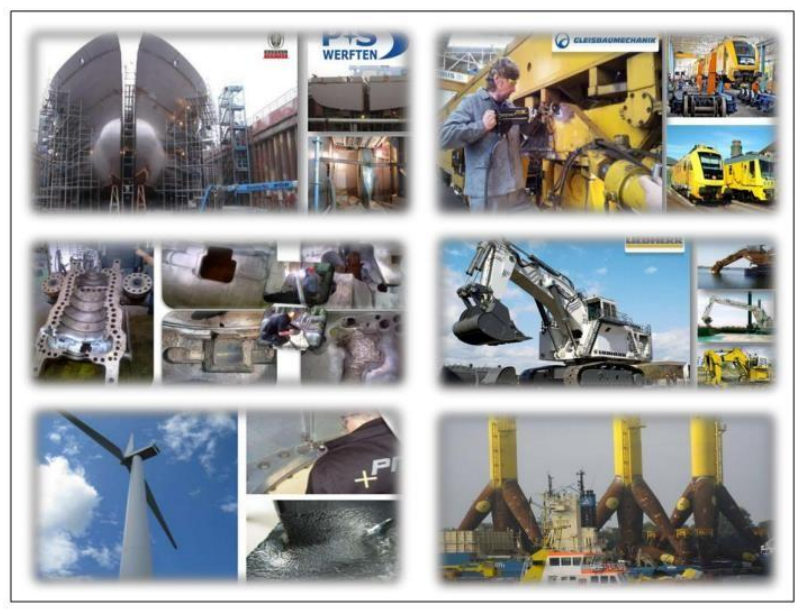

Fig. 21: Other examples of industrial application using HFMI/PIT

\section{Current Research at AMTEx UITM Shah Alam towards Weld Fatigue Integrity}

In an attempt to address the deteriorating magnitude of tensile residual stress remaining in a typical friction stir welding (FSW), Advanced Manufacturing Technology Excellence Centre a.k.a AMTEx at Faculty of Mechanical Engineering in UiTM Shah Alam used the HFMI/PIT method to enhance the fatigue life cycle of AA 6061-T6 FSW $6 \mathrm{~mm}$ butt joints for as-welded and pre-fatigued conditions.

The AA 6061-T6 was used due to the acceptance of this material in a vast number of industrial application such as the railway, locomotive, automotive and aerospace industries. For the aswelded conditions, two plates with the dimension of $100 \mathrm{~mm}$ width and $500 \mathrm{~mm}$ of length was friction stir welded via a milling machine with a rotation speed of $950 \mathrm{rpm}$ and a traverse speed of $1.42 \mathrm{~mm} / \mathrm{s}$ using a cylindrical tool as shown in Fig. 22. The joints were then machined into fatigue test specimens in accordance to ISO/TR 14345:2012 specifications as shown in Fig. 18. Fatigue test were executed with a stress ration, $\mathrm{R}=0.1$ and a frequency of $25 \mathrm{~Hz}$ to obtain the S-N curve. The result obtained is depicted in Fig. 23.

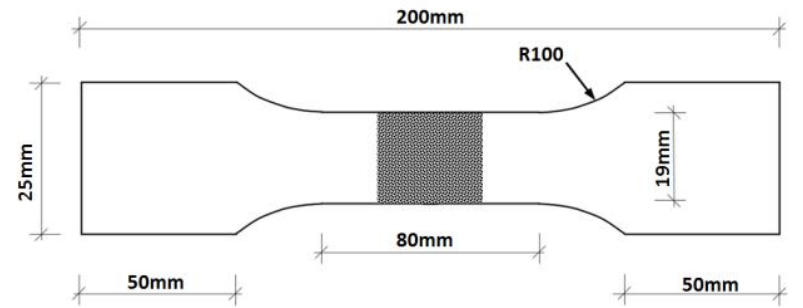

Fig. 22: Dimension of the flat fatigue specimen

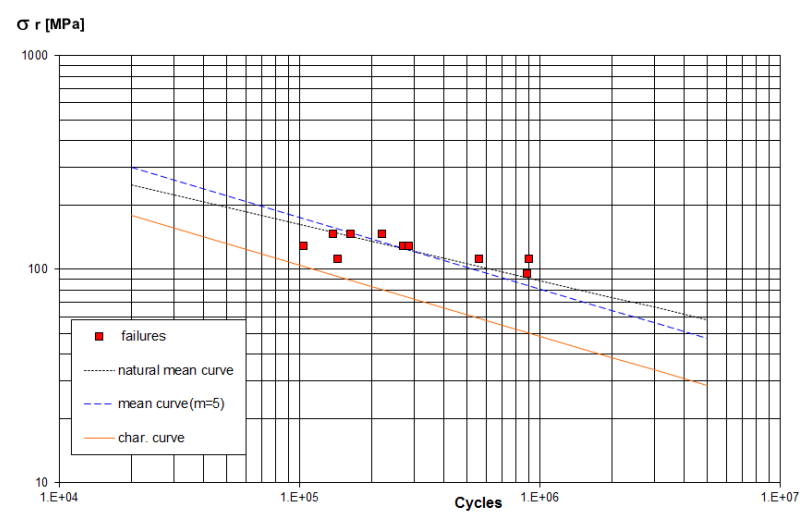

Fig. 23: S-N curve for FSW AA6061-T6 as welded condition

The pneumatic impact treatment was further used to enhance the fatigue life of an axially loaded friction stir welded aluminum alloy butt joint with a thickness of $6 \mathrm{~mm}$. Following the procedures outlined to produce the FSW as-welded fatigue test specimens, the test coupons were then axially loaded with a 75 percent loading capacity of the tensile strength of $171 \mathrm{Mpa}$ to a number of 300,000 cycles amounting to 80 percent of the cycles to failure. The specimens were then HFMI/PIT treated before fatigue tests were accomplished with a ratio of $\mathrm{R}=0.1$ as well. The results are depicted in the Fig. 24 below. The results shows that the axially loaded HFMI/PIT treated joints can achieve a FAT 10MPa of increment in fatigue strength to the as welded in the region below one million cycles. However, a growth of $25 \mathrm{MPa}$ is seen at the characteristic strength post HFMI/PIT, compared to the as-welded joints. 


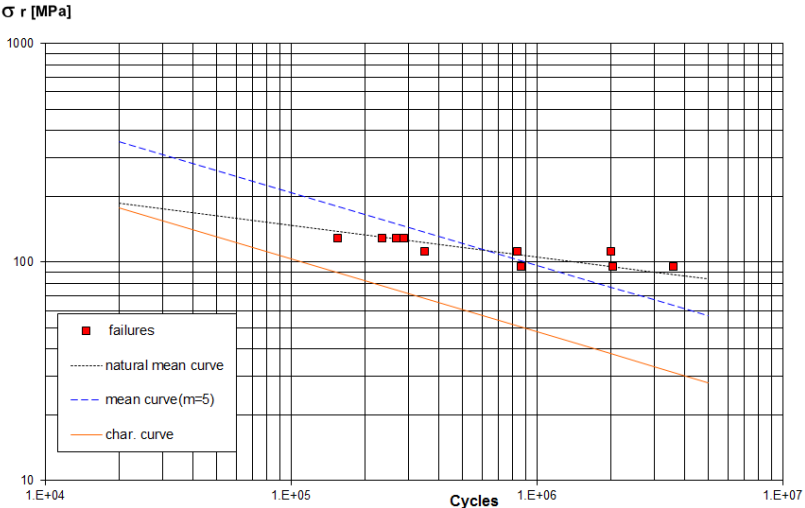

Fig. 24: S-N curve for FSW AA6061-T6 pre-fatigued HFMI/PIT treated condition

In addition to that, the FSW as-welded AA 6061-T6 joints were HFMI/PIT treated to evaluate the possible increment in the fatigue life cycle. The results are shown in Fig. 25. Table 6 shows the FAT values comparisons for friction stir welded, HFMI/PIT treated and axially loaded HFMI/PIT treated specimens. HFMI/PIT treated specimen display a fatigue life enhancement of $38 \mathrm{MPa}$ in the FAT value compared to the as-welded conditions.

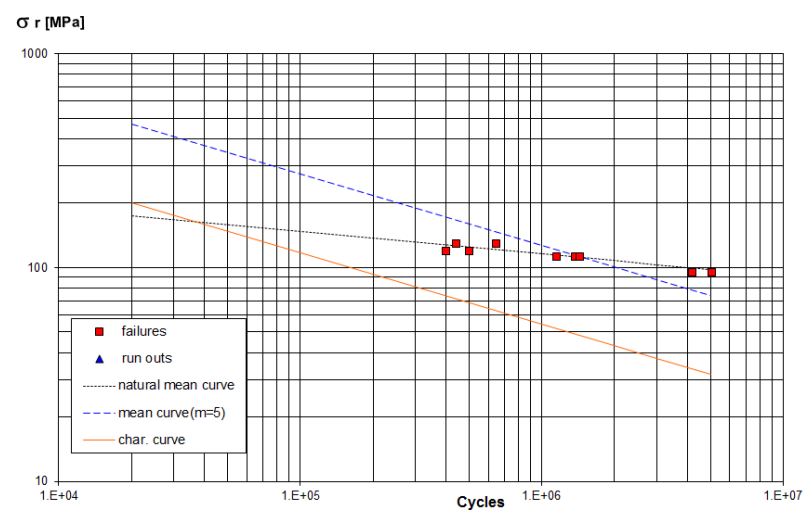

Fig. 25: S-N curve for FSW AA6061-T6 HFMI/PIT treated condition

Table 6 shows the FAT values comparisons for friction stir welded

\begin{tabular}{|l|c|}
\hline \multicolumn{1}{|c|}{ Type } & FAT value \\
\hline Base Material (AA 6061) & $140 \mathrm{MPa}$ \\
\hline Friction Stir Welded (as-welded) & $68 \mathrm{MPa}$ \\
\hline Pre-fatigued HFMI/PIT treated & $93 \mathrm{MPa}$ \\
\hline FSW HFMI/PIT treated & $105 \mathrm{MPa}$ \\
\hline
\end{tabular}

Other current research at AMTEx is to investigate the effect of HFMI/PIT on welded structure using matched and under-matched filler material. A series of specimens of the welded plate of A36 were treated using HFMI/PIT before undergo tensile test. The material was joined using GMAW process using consumable ER70S-6 which has compatible strength with the minimum strength of the material A36. It can be seen from Table 7 that the tensile strength is increased after treatment.

Table 7: Tensile test results of carbon steel A36

\begin{tabular}{|c|c|}
\hline Condition & Average Tensile Strength (MPa) \\
\hline As welded & 223.515 \\
\hline $\begin{array}{c}\text { HFMI/PIT } \\
\text { treated }\end{array}$ & 365.467 \\
\hline
\end{tabular}

Further, a series of specimens of the welded high strength low alloy steel (HSLA) S460G2+M were treated using HFMI/PIT before undergo tensile test. Initially this material was joined using GMAW process using consumable ER70S-6 which has noncompatible strength with the standard minimum tensile strength of the HSLA plate. Eventually, the results show an increment of the strength which is compatible with the tensile strength of the base material and as welded material of the HSLA plate S460G2+M as presented in Table 8. The results indicate small increments of strength percentage values of the treated tensile specimens.

Table 8: Comparison of tensile strength of $S 460 G 2+M$

\begin{tabular}{|c|c|c|c|}
\hline Condition & $\begin{array}{c}\text { Tensile } \\
\text { specimen } \\
\text { ID }\end{array}$ & $\begin{array}{c}\text { Tensile } \\
\text { Strength } \\
\text { (MPa) }\end{array}$ & \multirow{2}{*}{$\begin{array}{c}\text { Average } \\
\text { (MPa) }\end{array}$} \\
\hline Raw & T1 & 585.65 & \multirow{2}{*}{584.20} \\
\cline { 2 - 3 } Material & $\mathrm{T} 2$ & 582.75 & \\
\hline \multirow{2}{*}{ As Welded } & $\mathrm{T} 3$ & 603.76 & \multirow{2}{*}{598.09} \\
\cline { 2 - 3 } & $\mathrm{T} 4$ & 592.42 & \\
\hline \multirow{3}{*}{$\begin{array}{c}\text { HFMI/PIT } \\
\text { Treated }\end{array}$} & $\mathrm{T} 5$ & 584.08 & \multirow{2}{*}{609.11} \\
\cline { 2 - 3 } & $\mathrm{T} 6$ & 630.93 & \\
\cline { 2 - 3 } & $\mathrm{T} 7$ & 589.15 & \\
\cline { 2 - 3 } & $\mathrm{T} 8$ & 632.27 & \\
\hline
\end{tabular}

\section{Conclusion}

Life extension, as a part of asset integrity management which is essential for ensuring a safe and sustainable industry, involves maintaining hardware to be safe, reliable and efficient. Especially for offshore oil and gas installations, which are supposed to be constructed to last for decades, are frequently situated in challenging environments and are vulnerable to extreme weather and operational conditions. Hence, maintaining asset integrity is a challenge which oil and gas industry should take seriously. Moreover, asset integrity forms a key part of in safety's strategy. 
Finally, the review on researches and applications can be summarized as follow:

- In general, high fatigue strength of welded structure can be achieved by: (1) Good design practice, (2) High quality fabrication and (3) Improvement method.

- Peening technology as improvement method is already recognized by numerous rules and standards such as ABS and AWS to control shrinkage stresses, prevent cracking and mitigate distortion.

- New improvement method HFMI/PIT can increase fatigue life, fatigue strength and stress corrosion resistance.

- HFMI/PIT can be used for preventive and corrective maintenance or for rehabilitation and repair (atmospheric and underwater).

- HFMI/PIT can be used for optimization of new design and material usage.

- HFMI/PIT can be used on layer-by-layer welding to reduce residual stress and distortion.

- HFMI/PIT can be carried out based on FEM, past experiences or weld/suspect details.

- HFMI/PIT strengthens metals through cold work which can increase surface hardness providing increased resistance to wear and abrasion.

- HFMI/PIT strengthens welded joint of the structure metals through cold work even though using the unmatched consumable to the parent metal.

- Selection of HFMI devices is essential such as quality assurance methods (certification, inspection method), safety awareness, working potential/voltage (esp. for confined or wet area).

- Various applications of HFMI were reported ranging from offshore (duplex flow line, pontoon, aging rigs, FPSO, ship-shaped FPU etc), underwater structure, stainless steel boiler, train bogies, cranes, highway bridge up to heavy industrial crankshaft.

\section{Acknowledgement}

The authors would like to express their gratitude to staff members of Welding Laboratory and Advanced Manufacturing Laboratory at Faculty of Mechanical Engineering in UiTM Shah Alam for their support. A special thank is also directed to PITEC GmbH in Germany for providing the equipment and encouraging the team of Weld Fatigue Integrity with new knowledge and experience. The authors would like to thank all supporting companies (Nusantara Technologies
Sdn. Bhd. and Bogor Safety Institute) for providing welding specimens, test facility, standards and advices during the fatigue test and simulation process.

\section{References}

[1] A. Hobbacher, Recommendations for Fatigue Design of Welded Joints and Components, International Institute of Welding-IIW, document XIII-2151-07/XV-1254-07. Paris, France, May 2007.

[2] S. J. Maddox, 2003 IIW Portvin lecture: Key developments in the fatigue design of welded constructions. IIW Annual Assembly, (2003) PDCA12-70 data sheet, Opto Speed SA, Mezzovico, Switzerland.

[3] P. J. Haagensen, S. J Maddox, IIW Recommendations on Post Weld Fatigue Life Improvement of Steel and Aluminium Structures, International Institute of Welding, Paris, 2010.

[4] Key Programme 4 (KP4), Ageing and life extension programme, a report by the Energy Division of HSE's Hazardous Installations Directorate (Internet source: http://www.hse.gov.uk/offshore/ageing/kp4programme.htm).

[5] IIW Fatigue Recommendations XIII-246013/XV-1440-1 2013.C

[6] G. Marquis and Z. Barsoum, Fatigue strength improvement of steel structures by highfrequency mechanical impact: proposed procedures and quality assurance guidelines, Welding in the World, vol. 58, no. 1, pp. 1928, Jun. 2013.

[7] P. Gerster, F. Schäfers, and M. Leitner, Pneumatic Impact Treatment (PIT) Application and Quality Assurance, IIW Document XIII-WG2-138-13 pp. 1-11.

[8] U. Kuhlmann, Test Report: Investigations on the fatigue strength improvement of welded joints using Pneumatic Impact Treatment (PIT), University of Stuttgart,2013.

[9] U. Kuhlmann, T. Ummenhofer and U. Gabrys, Untersuchungen zur Anwendung höherfrequenten Hämmerverfahren im Stahlwasserbau, Test Report for BAW (Bundesanstalt fuer Wasserbau), 2014.

[10] Belgian Welding Institute, Summary of the results of the research project: Improvement of welded structures fatigue life in high strength steel grades (DURIMPROVE), Belgium, 2014.

[11] J. Berg and N. Stranghoener, Fatigue Strength of Welded Ultra High Strength Steels Improved by High Frequency Hammer 
Peening, Procedia Materials Science, vol. 3, pp. 71-76, 2014.

[12] H. C. Yildirim and G. B. Marquis, Fatigue strength improvement factors for high strength steel welded joints treated by high frequency mechanical impact, International Journal of Fatigue, vol. 44, pp. 168-176, 2012.

[13] M. Leitner, M. Stoschka, and W. Eichlseder, Contribution to the fatigue enhancement of thin-walled, high-strength steel joints by high frequency mechanical impact treatment, IIW Document XIII-2416-12pp. 1-15. D.

[14] D. Simunek, M. Leitner, and M. Stoschka, Numerical simulation loop to investigate the local fatigue behaviour of welded and HFMItreated joints, XIII-WG2-136-13 pp. 1-13.

[15] M. Leitner, S. Gerstbrein, M. J. Ottersböck, and M. Stoschka, Fatigue Strength of HFMItreated High-strength Steel Joints under Constant and Variable Amplitude Block Loading, Procedia Engineering, vol. 101, pp. 251-258, 2015.

[16] Martin Leitner, Michael Stoschka, Richard Schanner Wilfried Eichlseder; Influence of High Frequency Peening on Fatigue of HighStrength Steels, FME Transactions, vol.40, no.3, pp.99-104,2012

[17] M.laitner, Z,Barsoum, F.Schafers, Crack propagation analysis and rehabilitation by HFMI of pre-fatigue welded structure,Welding in the world, 2016

[18] H. C. Yildirim, G. B. Marquis, and Z. Barsoum, Fatigue assessment of high frequency mechanical impact (HFMI)improved fillet welds by local approaches, International Journal of Fatigue, vol. 52, pp. 57-67, 2013

[19] Th Nitschke-Pagel, H Eslami, Klaus Dilger, Influence the deformation intensity on the fatigue strength of aluminium welds with different mechanical surface treatments, International Institute of Welding, IIW-Doc. XIII-2483-13 pp. 1-14.

[20] H. C. Y1ldirım and G. B. Marquis, Fatigue design of axially-loaded high frequency mechanical impact treated welds by the effective notch stress method, Materials \& Design, vol. 58, pp. 543-550, 2014.

[21] G. B. Marquis, E. Mikkola, H. C. Yildirim, and Z. Barsoum, Fatigue Strength Improvement of Steel Structures by HFMI: Proposed Fatigue Assessment Guidelines. IIW doc. XIII-2452r1-13.

[22] G. Marquis and Z. Barsoum, Fatigue strength improvement of steel structures by high- frequency mechanical impact: proposed procedures and quality assurance guidelines, Welding in the World, vol. 58, no. 1, pp. 19 28, 2013.

[23] G. Marquis and Z. Barsoum, Fatigue strength improvement of steel structures by highfrequency mechanical impact: proposed procedures and quality assurance guidelines, Welding in the World, vol. 58, no. 1, pp. 1928, 2013.

[24] G. Marquis, and Z. Barsoum, Fatigue Strength Improvement of Steel Structures by HFMI: Proposed Procedures and Quality Assurance Guidelines, International Institute of Welding, Paris, IIW Document XIII-2453-13, 2013.

[25] H. C. Yildirim, G. B. Marquis, and Z. Barsoum, Fatigue Assessment of High Frequency Mechanical Impact (HFMI) Improved Fillet Welds by Local Approaches, International Journal of Fatigue, vol 52, pp. 57-67, 2013.

[26] S. J. Maddox, M. J. Dore, S. D. Smith, Investigation of ultrasonic peening for upgrading a welded steel structure. International Institute of Welding, Paris, IIW Doc. XII232610, 2010.

[27] Linde Engineering Division, Einfluss des Haemmerns auf die Nahtschrumpfung, Germany, 2010.

[28] TUV SUD Industrie Service $\mathrm{GmbH}$, Einfuehrung des Eurocodes und Lebensdauerverlaengerung von Schweisskonstruktionen/Komponenten durch qualifizierte mechanische Nachbehandlung, Mannheim, Germany, 2014. 